\title{
Agronomic
}

\section{CARACTERÍSTICAS MORFOLÓGICAS E PRODUTIVAS NA CULTURA DO MILHO}

\author{
MORPHOLOGICAL AND PRODUCTIVE CHARACTERISTICS IN CORN CULTURE
}

Raniel Candido de Oliveira ${ }^{1}$; Dyb Youssef Bittar ${ }^{2 *}$; Ayure Gomes da Silva ${ }^{2}$; Gustavo Henrique Mendes Brito $^{2}$

${ }^{1}$ Discente do Curso de Bacharelado em agronomia da Faculdade Evangélica de Goianésia

2 Docente do Curso de Bacharelado em Agronomia da Faculdade Evangélica de Goianésia-dybittar@hotmail.com

\section{Info}

Recebido: 01/2019

Publicado: 03/2019

ISSN: 2595-6906

\begin{tabular}{l}
\hline Palavras-Chave \\
ZeaMays, Adubação; Dose no plantio \\
Keywords: \\
Zea Mays, fertilizing; time of \\
application
\end{tabular}

\begin{abstract}
O objetivo foi identificar qual a melhor dose de Fósforo no plantio do milho (ZeaMays). 0 experimento foi conduzido na Fazenda Assentamento presente de Deus, Goianésia- Goiás. 0 delineamento experimental empregado foi o de blocos casualizados com cinco tratamentos e cinco repetições (5x2). Foi realizado plantio em diferentes doses de Fósforo, sendo 0 kg de P/ha-1(T1- Testemunha), $60 \mathrm{~kg}$ de P/ha-1( T2), $90 \mathrm{~kg}$ de P/ha-1(T3), $120 \mathrm{~kg}$ de P/ha-1(T4) e $150 \mathrm{~kg}$ de P/ha-1(T5) . As características morfológicas avaliadas foram: altura de planta, diâmetro de colmo, altura de primeira espiga, diâmetro da espiga, número de fileiras na espiga, número de grãos por fileiras, massa seca e massa verde da planta e da espiga. Foi constatado que a adubação de $\mathrm{P}$ no tratamento T1 até T4 teve um aumento na produção do milho e no
\end{abstract} tratamento T5 não houver aumento, em caso de algumas características morfológicas, como número de fileira de grão, diâmetro da espiga, que teve aumentaram com o tratamento T5, $150 \mathrm{~kg}$ de P/ha-1,, com maior produtividade da espiga. Assim, pelos dados obtidos, a dose mais utilizada para a produção do milho e do tratamento T4.

\section{Resumo}

The objectiveofthisworkwastoidentifythebest dose of P in maize (ZeaMays). The experimentwascarried out atthePresentSettlementFarmofGod, Goianésia-Goiás. The experimental design was a randomizedblockwithfivetreatmentsandfivereplications. P / ha-1 (V1 Witness), $60 \mathrm{~kg}$ P / ha-1 (V2), 90 $\mathrm{kg} \mathrm{P} \mathrm{/} \mathrm{ha-1} \mathrm{(V3),} 120 \mathrm{~kg}$ of $\mathrm{P} / \mathrm{ha}-1$ (V4) and $150 \mathrm{~kg}$ of $\mathrm{P} /$ ha-1 (V5). The morphologicalcharacteristicsevaluatedwere: plantheight, stalkdiameter, firstearheight, eardiameter, numberofrows in ear, numberofgrains per row, drymassandgreenmassofplantandear. It wasverifiedthatthefertilization of $\mathrm{P}$ in thetreatment $\mathrm{V} 1$ to $\mathrm{V} 4$ hadanincrease in thecornproductionand in thetreatment V5 therewas no increase, in the case of some morphologicalcharacteristics, as rownumberofgrain, eardiameter, whichhadincreasedwiththetreatment V5, $150 \mathrm{~kg}$ of P / ha- 1 . Thus, bythe data obtained, themostused dose for maizeproductionand V4 treatment. 


\section{INTRODUÇÃO}

No Brasil, a cultura do milho tem-se caracterizado pelo seu alto potencial produtivo, sendo cultivado em duas épocas de plantio a safra (outubro a janeiro) e safrinha (janeiro a fevereiro)com uma produção estimada em aproximadamente 40,8 milhões de tonelada sem uma área de aproximadamente 12,55 milhões de hectares. (CRUZ, et, al, 2010). Em Goiás o milho representa a $4^{\circ}$ posição na produção de Grãos (SEIXAS, 2017).

A eficiência na promoção do crescimento e produtividade do milho, assim com o fornecimento varia conforme a fonte de fósforo. As principais fontes encontradas e utilizadas para suprir essa demanda, são: Fosfatos naturais que apresentam menor eficiência inicial, porém custo mais baixo, enquanto que fosfatos mais solúveis como o superfosfato simples; superfosfato triplo ou concentrado proporciona maior resposta biológica com um custo mais alto (GIRACCA E NUNES, 2016)

O fósforo é um elemento químico encontrado em baixas concentrações em solos de cerrado, sendo necessário o seu fornecimento em doses relativamente altas para o cultivo do milho, pois a sua deficiência interfere na formação e desenvolvimento dos grãos, contribuindo na formação de espigas mal formadas, tortas e com falhas, maturação retardada e desuniforme ocasionando, a baixa produtividade (PADROET et al, 2001).

A cultura do milho tem exigência de fósforo em maior quantidade aos 35 a 40 dias após a germinação até o florescimento. Por ser um período do estágio vegetativo, com extrema exigência de fósforo, e um nutriente com pouca mobilidade no solo, deve ser aplicado toda exigência no sulco durante o plantio (VASCONSELLOS, et, al 2000).

Neste sentido, o objetivo com este trabalho foi verificar qual a melhor dosagem de fósforo na cultura do milho (ZeaMays),na adubação localizada no sulco.

\section{MATERIAL E MÉTODOS}

\section{Caracterização da área experimental}

A coleta dos dados foi realizada na Fazenda Assentamento Presente de Deus, localizada no município de Goianésia- GO, região centro-oeste do estado e está situado nas coordenadas geográficas 1519'33.0”S 049¹7'59.2” W, com altitude de $570 \mathrm{~m}$. De acordo com a classificação de KOOPEN o clima da região é do tipo AW, que significa clima tropical com estação seca no inverno., com duas estações bem definidas: à estação seca que se inicia em abril e se estende até a primeira quinzena de outubro e a estação chuvosa que termino na segunda quinzena de outubro e se estende até o mês de março do ano seguinte.

O experimento foi instalado em um solo Latossolo Vermelho, com textura argilosa. Para a caracterização química do solo, foram coletadas amostras de solo cerca de três meses antes da instalação do experimento.

A metodologia empregada para todas as análises do solo seguiu as recomendações da Embrapa (SOUSA et al., 2004), e foram realizadas no Laboratório de Solos Unisolo - Goianésia - GO, e apresentou como propriedades químicas e físicas do solo, Tabela 1: 
Tabela 1: Analise de solo

\begin{tabular}{|c|c|c|c|c|c|c|c|c|c|c|c|c|}
\hline \multicolumn{3}{|c|}{ Indetificação } & \multicolumn{10}{|c|}{ Dados Analíticos } \\
\hline \multirow{2}{*}{ Lab. } & \multirow{2}{*}{ Cliente } & \multirow{2}{*}{ Prof. } & $\mathrm{pH} \mathrm{H} 2 \mathrm{O}$ & $\mathrm{pH} \mathrm{CaCl}$ & M.O & C.O & $\mathrm{P}$ meh & $\mathrm{K}+$ & $\mathrm{Ca} 2+$ & $\mathrm{Mg} 2+$ & $\mathrm{Al} 2+$ & $\mathrm{H}+\mathrm{Al}$ \\
\hline & & & & & \multicolumn{2}{|c|}{$\mathrm{mg} \mathrm{dm}-{ }^{3}$} & \multicolumn{2}{|c|}{$\mathrm{mg} \mathrm{dm}-^{3}$} & \multicolumn{4}{|c|}{ cmolc dm- ${ }^{3}$} \\
\hline 4023 & única & $0-25$ & & 0 & 30,4 & 17,7 & 11,0 & 75,0 & 4.97 & 0.00 & 4.18 & \\
\hline
\end{tabular}

\begin{tabular}{|c|c|c|c|c|c|c|c|c|c|c|c|c|}
\hline & detificaçã & & \multicolumn{10}{|c|}{ Dados Adicionais } \\
\hline \multirow[t]{2}{*}{$\mathrm{Lab}$} & \multirow[t]{2}{*}{ Cliente } & \multirow[t]{2}{*}{ Prof } & $\mathrm{Ca}+\mathrm{Mg}$ & $\mathrm{Ca} / \mathrm{Mg}$ & $\begin{array}{l}\text { CTC } \\
\mathrm{T} \\
\end{array}$ & $\begin{array}{l}\text { CTC } \\
\mathrm{t} \\
\end{array}$ & Soma B & $\mathrm{Ca} / \mathrm{CTC}$ & MG/CTC & $\mathrm{K} / \mathrm{CTC}$ & HAL/CTC & sat bases \\
\hline & & & $\mathrm{cmlo} \mathrm{dm}$ & & \multicolumn{3}{|c|}{ cmolc dm $-^{3}$} & \multicolumn{5}{|c|}{$\%$} \\
\hline 4023 & única & $0-25$ & 5,93 & 5,18 & 10,3 & 6,12 & 6,12 & 48 & 9,3 & 1,9 & 40,6 & 59 \\
\hline
\end{tabular}

\begin{tabular}{|c|c|c|c|c|c|c|c|c|c|c|c|}
\hline \multicolumn{3}{|c|}{ Indetificação } & \multicolumn{5}{|c|}{ Dados Analíticos } & \multicolumn{3}{|c|}{ Textura } & \\
\hline \multirow{2}{*}{$\mathrm{Lab}$} & \multirow{2}{*}{ Cliente } & \multirow{2}{*}{ Prof } & B & $\mathrm{Cu}$ & $\mathrm{Fe}$ & $\mathrm{Mn}$ & $\mathrm{Zn}$ & Argila & Silte & Areia & P rem \\
\hline & & & \multicolumn{5}{|c|}{$\mathrm{mg} \mathrm{dm}-^{3}$} & \multicolumn{3}{|c|}{$\mathrm{g} / \mathrm{kg}$} & $\mathrm{mg} \mathrm{dm}^{3}$ \\
\hline 4023 & única & $0-25$ & & & & & & 4 & 26 & 255 & \\
\hline
\end{tabular}

O delineamento estatístico empregado foi de blocos inteiramente casualizados, com cinco tratamentos e cinco repetições $(5 \times 2)$, implantando no dia 05 de janeiro de 2018. Os tratamentos foram compostos pela avaliação de quatro doses de fósforo juntamente no plantio, sendo, T1testemunha ( $0 \mathrm{~kg} / \mathrm{ha})$, T2 (60 kg/ha-1), T3 (90 kg/ha), T4 (120 kg/ha-1), T5 $\left(150 \mathrm{~kg} / \mathrm{ha}^{-1}\right)$ e aplicando adubação de cobertura com uréia $\left(133 \mathrm{~kg} / \mathrm{ha}^{-1}\right)$ e um tratamento adicional como testemunha, sem aplicação de $\mathrm{P}$, totalizando 25 tratamentos. O milho utilizado foi o Genótipo SYN8A98 FEROZ VIP TC P 24C.

No preparo de solo, foi realizada a dessecação (ZAPP QI 620), aração e gradagem no sistema convencional de plantio. O plantio foi realizado dia 05 de janeiro de 2018, com semeadura manual e espaçamento de $1 \mathrm{~m}$ entre linhas e $0,25 \mathrm{~cm}$ entre plantas, totalizando 6 sementes $/ \mathrm{m}$ linear. As dosagens do delineamento experimental foram determinadas a partir da formulação 03-17-00 (superfosfato simples) e na adubação de cobertura foi utilizado o total de 133 $\mathrm{kg} / \mathrm{ha}^{-1}$ de uréia. As adubações de cobertura foram realizadas aos 30 dias após a germinação. O controle das plantas daninhas da área com capina manual. As adubações de cobertura foram realizadas nas linhas de plantio, sempre em condições ideais de umidade possíveis.

Aproximadamente aos 90 dias após a semeadura foram coletadas as amostras para avaliação dos componentes de produção: altura de planta (AP), diâmetro de colmo (DC), altura da primeira espiga (APE), número de fileiras da espiga (NFE), número de grão por fileira (NGF) e diâmetro da espiga (DE),sendo posteriormente avaliado massa seca planta (MSP), massa verde planta (MVP), massa seca espiga (MSE) e massa verde espiga(MVE).

O diâmetro de colmo foi definido com a média de 10 plantas por parcela, sendo avaliado no terço médio da planta com o auxílio de um paquímetro em milímetros. A altura da planta foi medida da superfície do solo até a última folha expandida, com o auxílio de uma trena graduada em centímetros. A altura da espiga, foi medida da superfície do solo, até a inserção da primeira espiga com o auxílio de uma trena graduada em centímetros. 
O diâmetro da espiga foi definido com a média de 10 plantas por cada parcela útil, medido com o auxílio de um paquímetro em milímetros.

Para o número de fileiras da espiga foi contando a quantidade de fileiras da espiga de cada planta. $\mathrm{Na}$ mesma espiga foi contado o número de grãos por fileira.

Para a massa verde, utilizou-se duas plantas de cada parcela útil, trituradas em uma forrageira, e logo após pesado verde, para determinação da massa verde. Para a massa seca foram colocadas as amostras em uma estufa com $68^{\circ} \mathrm{C}$ por 72 horas, e depois pesado com o auxílio de uma balança digital.

\section{RESULTADOS E DISCUSSÃO}

Durante o experimento a distribuição de chuva foi provavelmente satisfatória para o ciclo da cultura, a precipitação foi de392,2 mm (INMET, 2018) desde o plantio, da germinação aos estádios vegetativos, florescimento e enchimento de grãos. De acordo com
Machado (2016), a cultura do milho e necessária400 a $600 \mathrm{~mm}$ de precipitação no verão, para obter uma boa produtividade, conforme a exigência da cultura.

De acordo com a análise de regressão, ocorreu efeito significativo $(\mathrm{p} \leq 0,01)$ dos tratamentos de fósforo sobre as variáveis analisadas. Observa-se que nas Tabelas 01, 02 e 03, onde estão apresentados no quadro de análise os resultados obtidos, onde mostra os resultados significativo a $(\mathrm{p} \leq 0,01)$, com as características significativa de cada análise, e suas fontes de variação, sendo a com maior resultando e a regressão linear, pelo fato de todas as características ser significativa a $1 \%$.

Tabela 2. Análise de regressão das características significativa de cada analise, altura de planta, altura da primeira espiga, número fileira da espiga e número de grãos por fileira, submetidos a diferentes doses de fósforo no plantio, com a cultura do milho (Zeamays L.)

\begin{tabular}{|c|c|c|c|c|c|}
\hline \multirow[b]{2}{*}{ Fontes de variação } & \multirow[b]{2}{*}{$\begin{array}{l}\text { Grau de } \\
\text { liberdade }\end{array}$} & \multicolumn{4}{|c|}{ Quadrado de Analise Regressão } \\
\hline & & $\begin{array}{c}\text { Altura da } \\
\text { Planta }\end{array}$ & $\begin{array}{c}\text { Altura da } \\
\text { Primeira } \\
\text { espiga }\end{array}$ & $\begin{array}{c}\text { Número fileira } \\
\text { da espiga }\end{array}$ & $\begin{array}{l}\text { Número de grão } \\
\text { por fileira }\end{array}$ \\
\hline Regressão.linear & 1 & 44.35 ** & $52.63 * *$ & $96.05 * *$ & 13.54 ** \\
\hline Regressão.quadratica & 1 & $10.78^{* *}$ & $0.36 \mathrm{~ns}$ & $8.34 * *$ & $12.42 * *$ \\
\hline Regressão.cúbica & 1 & $4.17 \mathrm{~ns}$ & $15.88^{* *}$ & $0.11 \mathrm{~ns}$ & $0.58 \mathrm{~ns}$ \\
\hline Regressão. $4^{\circ}$ grau & 1 & $13.84 * *$ & $2.97 \mathrm{~ns}$ & 1.35 ns- & $0.0034 \mathrm{~ns}$ \\
\hline Tratamentos & 5 & $18.29--$ & $17.96--$ & $26.46-$ & 6.64-- \\
\hline Resíduo & 20 & & & & \\
\hline MG & & 2.39 & 1.26 & 17.92 & 31,00 \\
\hline CV\% & & 3.87 & 3.90 & 6.93 & 14.87 \\
\hline
\end{tabular}

* significativo ao nível de $5 \%$ de probabilidade. ${ }^{\text {ns }}$ não significativo. ${ }^{* *}$ significativo ao nível de $1 \%$ de probabilidade. 
Tabela 3. Análise de regressão das características significativa de cada analise, diâmetro da espiga, massa seca da espiga, massa verde da espiga e massa verde da planta, submetidos a diferentes doses de fósforo no plantio, com a cultura do milho (Zeamays L.).

\begin{tabular}{|c|c|c|c|c|c|}
\hline \multirow[b]{2}{*}{ Fontes de variação } & \multirow[b]{2}{*}{$\begin{array}{l}\text { Grau de } \\
\text { liberdade }\end{array}$} & \multicolumn{4}{|c|}{ Quadrado de AnaliseRegressão } \\
\hline & & $\begin{array}{l}\text { Diâmetro } \\
\text { da espiga }\end{array}$ & $\begin{array}{l}\text { Diâmetro } \\
\text { do colmo }\end{array}$ & $\begin{array}{c}\text { Massa seca da } \\
\text { espiga }\end{array}$ & $\begin{array}{c}\text { Massa verde da } \\
\text { espiga }\end{array}$ \\
\hline Regressão.linear & 1 & $22.71 * *$ & $206.25^{* *}$ & $28.83^{* *}$ & $56.27 * *$ \\
\hline Regressão.quadrática & 1 & $0.11 \mathrm{~ns}$ & $25.50^{* *}$ & $08.19 * *$ & $3.73 \mathrm{~ns}$ \\
\hline Regressão.cúbica & 1 & $0.12 \mathrm{~ns}$ & $10.56^{* *}$ & $0.08 \mathrm{~ns}$ & $0.16 \mathrm{~ns}$ \\
\hline Regressão.4 $4^{\circ}$ grau & 1 & $0.19 \mathrm{~ns}$ & $7.04 *$ & $1.98 \mathrm{~ns}$ & $1.31 \mathrm{~ns}-$ \\
\hline Tratamentos & 5 & $6.22--$ & $62.34--$ & $9.77--$ & 11.46-- \\
\hline Resíduo & 20 & & & & \\
\hline MG & & 48.68 & 21.52 & 0.16 & 0.22 \\
\hline $\mathrm{CV} \%$ & & 5.73 & 6.27 & 16.43 & 14.16 \\
\hline
\end{tabular}

* significativo ao nível de $5 \%$ de probabilidade. ${ }^{\text {ns }}$ não significativo. ${ }^{* *}$ significativo ao nível de $1 \%$ de probabilidade.

Fonte: o próprio autor

Tabela 4- Análise de regressão das características significativa de cada analise, massa seca da espiga, submetidos a diferentes doses de fosforo no plantio, coma cultura do milho (ZeamaysL.).

\begin{tabular}{lccc} 
& & \multicolumn{2}{c}{ Quadrado de Analise Regressão } \\
\cline { 3 - 4 } Fontes de variação & $\begin{array}{c}\text { Grau de } \\
\text { liberdade }\end{array}$ & Massa verde da planta & $\begin{array}{c}\text { Massa seca da } \\
\text { planta }\end{array}$ \\
& & & $21.65^{* *}$ \\
Regressão.linear & 1 & $19.80^{* *}$ & $10.49^{* *}$ \\
Regressão.quadratica & 1 & $4.74^{* *}$ & $1.51 \mathrm{~ns}$ \\
Regressão.cúbica & 1 & $1.31 \mathrm{~ns}$ & $10.11^{* *}$ \\
Regressão.4 $4^{\circ}$ grau & 1 & $11.46--$ & $10.94--$ \\
\hline Tratamentos & 5 & & 0.36 \\
Resíduo & 25 & 0.10 & 20.04 \\
\hline MG & & 14.29 & \\
CV\% & & &
\end{tabular}

* significativo ao nível de $5 \%$ de probabilidade. ns não significativo. ${ }^{* *}$ significativo ao nível de1\% de probabilidade.

\section{Características da parte vegetativa}

\section{Altura de Planta e Espiga}

$\mathrm{Na}$ Figura 1, o resultado significativo a(p $\leq 0,01)$ com regressão linear a diferentes doses de P no solo, na altura de planta e altura da primeira espiga, sendo o coeficiente de determinação de 99 $\%$ e $91 \%$, verificaram que na altura de planta, no tratamento T1 (Testemunha) a'T4, ocorreu um acréscimo de $0.31 \mathrm{~m}$ de $2,19 \mathrm{~m}$ a 2,50 $\mathrm{m}$ na altura da planta, e no tratamento T4 a T5 ocorreu o decréscimo de 0.01 de $2,50 \mathrm{~m}$ a 2,49 $\mathrm{m}$.
$\mathrm{Na}$ altura da primeira espiga (Figura 1), obteve resultando da altura da primeira espiga de $1,13 \mathrm{~m}$ a $1.25 \mathrm{~m}$, o tratamento T1(Testemunha) e T2, e um acréscimo na altura da primeira espiga, e no tratamento T2a T3 de $1.25 \mathrm{~m}$ a $1.30 \mathrm{~m}$, e no tratamento T3 eT4, houve um decréscimo na altura da primeira espiga de 1,3 m a 1,24 m, e como observado na figura 1, o tratamentoT4 a T5, houver um desenvolvimento maior na altura da primeira espiga, de $1.24 \mathrm{~m}$ a $1.39 \mathrm{~m}$. 
Figura 1: Diferente doses de fosforo no plantio, comresultando significativo da altura da planta e altura da primeira espiga.

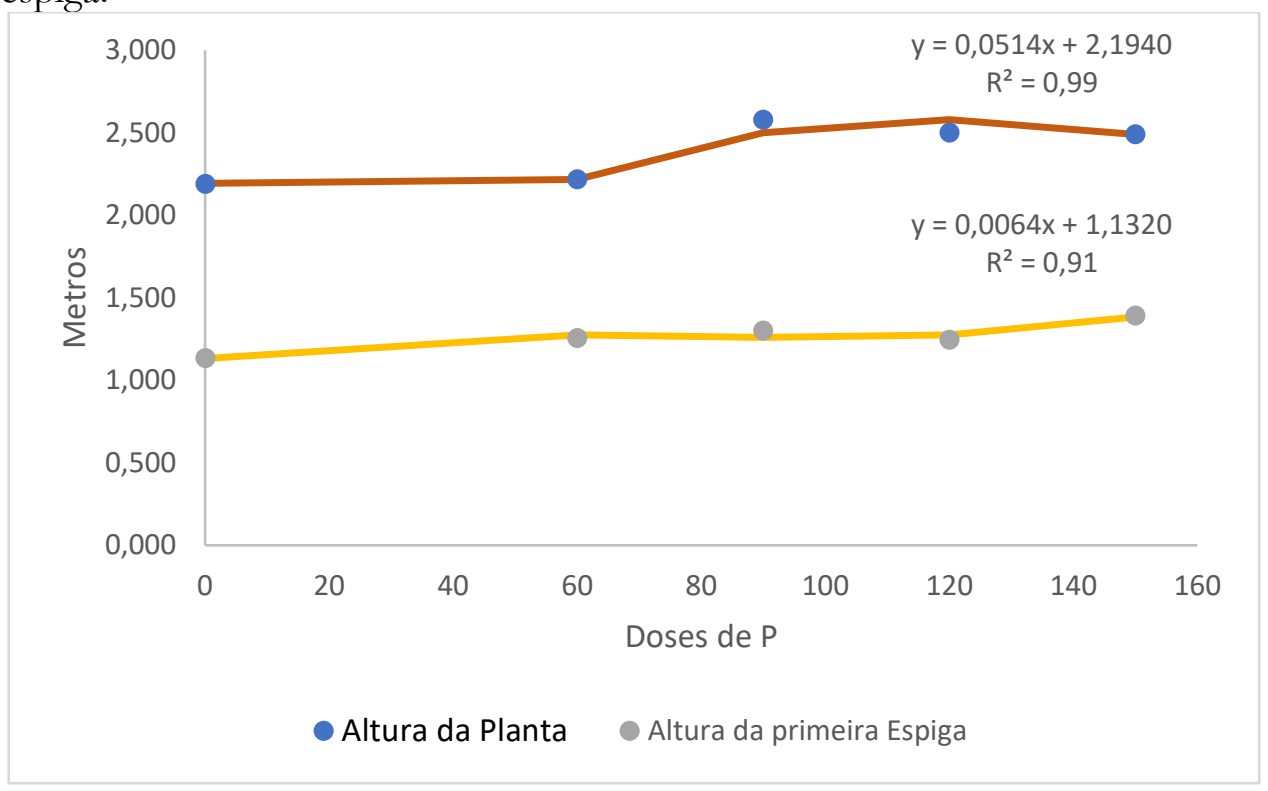

Para altura de planta apenas o tratamento T5 apresentou decréscimo na altura, e já na altura da primeira espiga o tratamento T5 teve acréscimo.

Para a altura da planta da planta, foi observada a diferença nas dosagens do fósforo, as plantas adubadas nos tratamentos T1, T2, T3, e T4, tiveram um acréscimo na altura da planta, observando que teve resultando apenas até tratamento $\mathrm{T} 4$, tendo decréscimo na altura da planta no tratamento V5.

De acordo com Lucena et al, (2000), a altura da planta está relacionada a dosagem de fósforo, em seu trabalho afirma que a planta de milho aumentou sua altura até 1,51 $\mathrm{m}$ na dosagemde177,3 $\mathrm{kg}$ de $\mathrm{P} / \mathrm{ha}^{-1} \mathrm{P}_{2} \mathrm{O}_{5}$ , na dosagem de $240 \mathrm{~kg}$ de $\mathrm{P} / \mathrm{ha}^{-1} \mathrm{P}_{2} \mathrm{O}_{5}$, começa a ocorrer decréscimo na altura da planta .

$\mathrm{Na}$ altura da primeira espiga a adubação de fósforo apresentou decréscimo no tratamento T3 para T4, com maior resultando no tratamento T5. De acordo Lima et al, (2016) a altura da primeira espiga pode estar relacionada ao acréscimo da dosagem de $\mathrm{P}$, pois em seu trabalho a altura da primeira espiga foi influenciado até a dose de $129 \mathrm{~kg}$ de $\mathrm{P} / \mathrm{ha}^{-1} \mathrm{P}_{2} \mathrm{O}_{5}$, ajustando com a equação quadrática, com decréscimo na dose de $180 \mathrm{~kg}$ de $\mathrm{P} / \mathrm{ha}^{-1} \mathrm{P}_{2} \mathrm{O}_{5}$.

\section{Diâmetro de Colmo}

Em relação ao diâmetro do colmo, em função as doses de $\mathrm{P}$, aplicados ao solo no plantio, verificou com o coeficiente de determinação de $99 \%$, entre os tratamentos V1(Testemunha) a V5, com resultando significativo a $(p \leq 0,01)$, com acréscimo no diâmetro V1(Testemunha)até a V5, de $13,6 \mathrm{~mm}$ a $25,8 \mathrm{~mm}$ (figura 2). 
Figura 2: Diferentes doses de fósforo no plantio, com resultando significativo dodiâmetro do colmo.

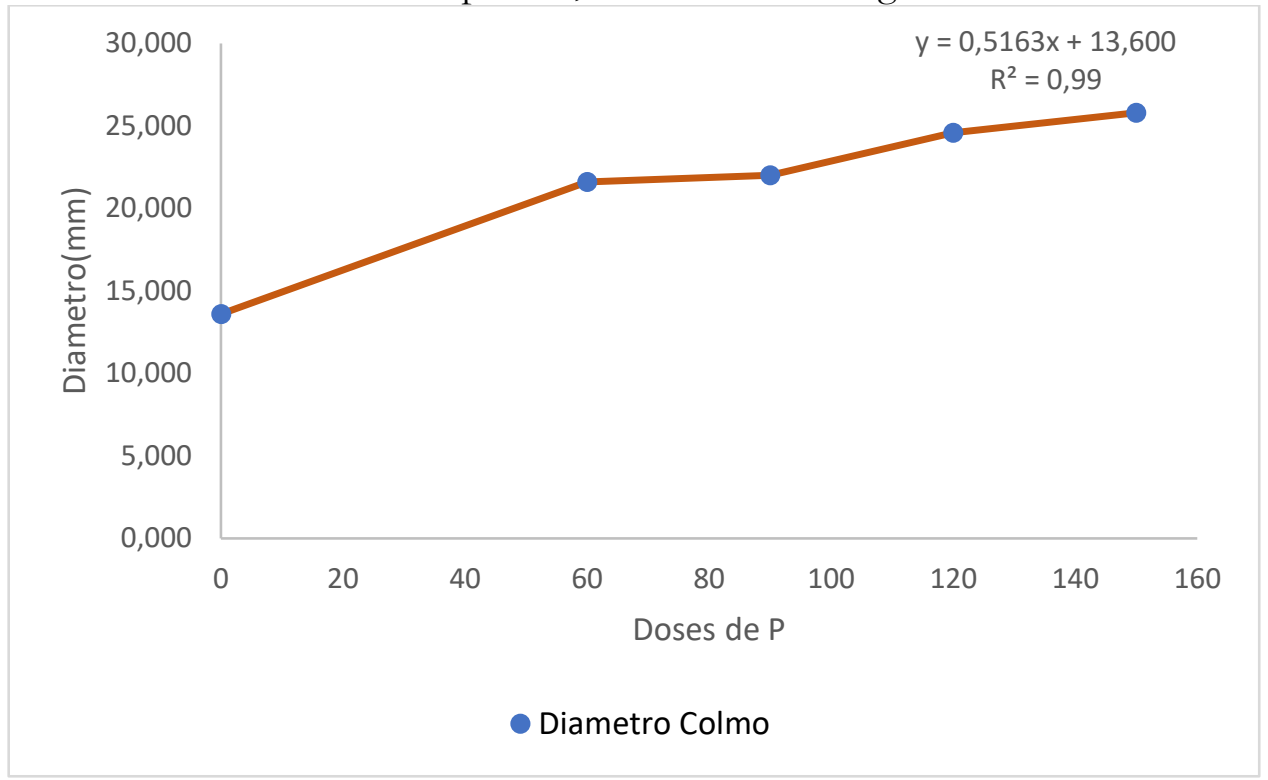

Os tratamentosT1, T2, T3, T4e T5, resultando com ajuste de regressão linear, com acréscimo de $13.6 \mathrm{~mm}$ a $25 \mathrm{~mm}$, do tratamento $\mathrm{T} 1$ ao tratamento $\mathrm{T} 5$, respondendo com resultando de acréscimo $11.4 \mathrm{~mm}$ do diâmetro do colmo no aumento das doses no plantio (Figura 2).

De acordo Lima et al., (2016), em seu trabalho observou que o diâmetro do colmo foi incrementado pelas doses de fósforo, ajustando pela regressão quadrática, com o ponto máximo de $115 \mathrm{~kg}$ $\mathrm{ha}^{-1}$ de $\mathrm{P}_{2} \mathrm{O}_{5}$, e com o decréscimo de $120 \mathrm{~kg}$ de $\mathrm{P} / \mathrm{ha}$ ${ }^{1} \mathrm{P}_{2} \mathrm{O}_{5}$ a $180 \mathrm{~kg}$ de $\mathrm{P} / \mathrm{ha}^{-1} \mathrm{P}_{2} \mathrm{O}_{5}$.

De acordo com SORAT'TO et al., (2010), quanto maior diâmetro do colmo, maior a possibilidade de favorecer positivamente os pontos agronômicos, pois o colmo é uma estrutura de reserva, armazenamento e translocação de fotoassimilados do colmo para os grãos, o que irar proporcionar o aumento da produção do milho.

\section{Características da parte reprodutiva}

\section{Número de grão fileira e número fileira espiga}

Verifica-se que quanto maior a dose de P nos tratamentos da Testemunha até o V5, maiores serão os números de grãos por fileira, com resultando significativo a $1 \%$, com coeficiente de determinação de $99 \%$, porém observa-se que T1(Testemunha) e'T3 teve aumento no número de grãos por fileira e deT3e T4 ocorreu uma estabilização dos valores seguido a partir da dose de $120 \mathrm{~kg}$ de $\mathrm{P} / \mathrm{ha}^{-1} \mathrm{~T} 4$ e de um decréscimo no fator de avaliação no T5.

Em relação a número fileira da espiga, com coeficiente de determinação $98 \%$, os melhores resultados, foram de T3 aT5, obtendo um acréscimo de 16 fileira a 22fileira( Figura 3). 
Figura 3: Diferentes doses de fósforo no plantio, com resultando significativo no número de Grãos por fileira e número de fileira por espiga.

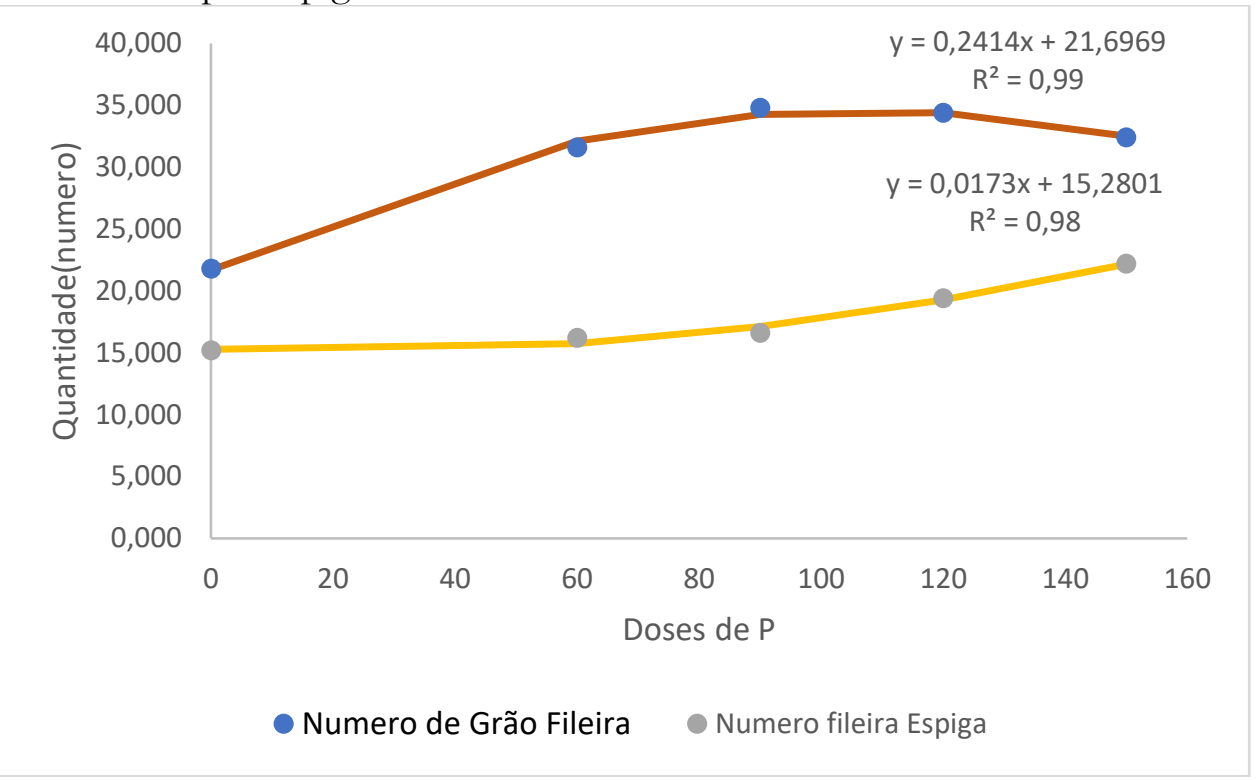

\section{Diâmetro da espiga}

Em relação ao diâmetro da espiga, quanto maior a dose de fósforo, T3a T5, maior o acréscimo no diâmetro da espiga, tendo resultados nas diferentes doses (Figura 4).

Figura 4: Diferentes doses de fósforo no plantio, com resultando de diferença significativa no diâmetro da espiga.

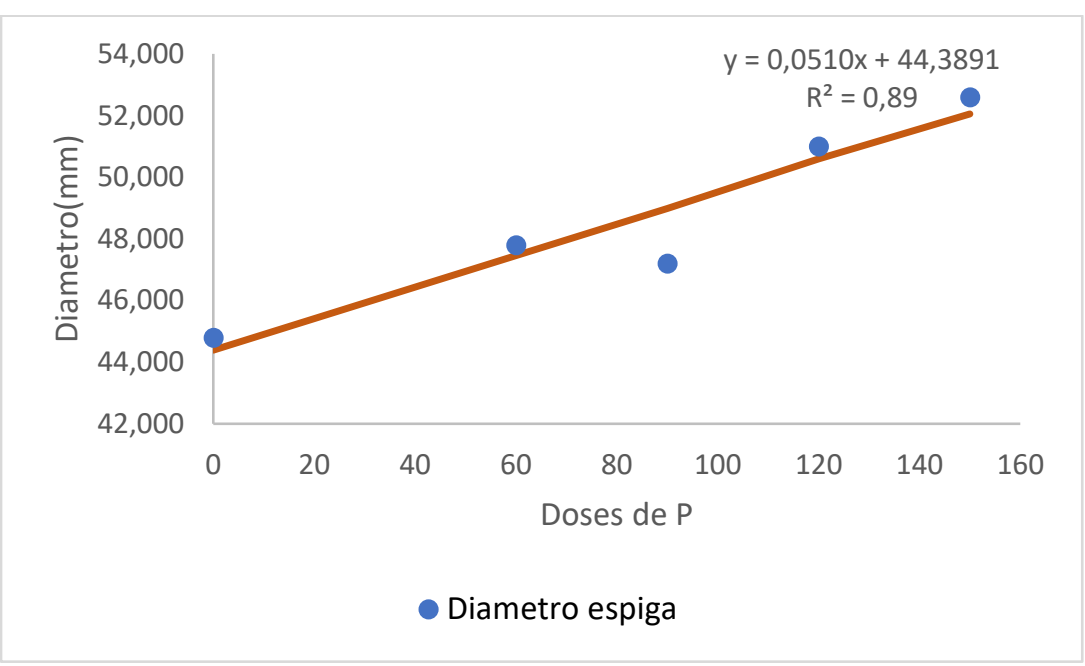

As doses de fósforo influenciaram no aumento do diâmetro da espiga, tendo acréscimo nos tratamentos com ajuste de regressão linear, de $44 \mathrm{~mm}$ a $52 \mathrm{~mm}$ no diâmetro da espiga.

De acordo com Padro et al, (2001), a aplicação de doses de fósforo crescentes irar aumenta a produção de grãos de milho, assim a adubação no plantio, seja ela localizada ou a lanço irar favorecer na produção de grãos, tendo resultados diferentes mais próximos, e com resultados na aplicação de $\mathrm{P}$ de adubação em manutenção, com aumento da produção de grãos.

\section{Características massa verde e massa seca}

\section{Peso massa verde espiga e peso massa seca}

Afigura abaixo (Figura 5), representa as diferentes doses de fósforo, com variações no peso de 
massa verde da espiga e peso massa seca da espiga, com o coeficiente de determinação de $93 \%$ e 97\%, com seus resultados significativos a $1 \%$, apresentado o efeito de regressão linear, e resultados de aumento da massa verde e massa seca, T1 (Testemunha), T4, noT4a V5, houve a diminuição na massa verde e massa seca.

Figura 5: Diferentes doses de fósforo no plantio, com resultando significativo no peso da massa seca e peso de massa verde da espiga.

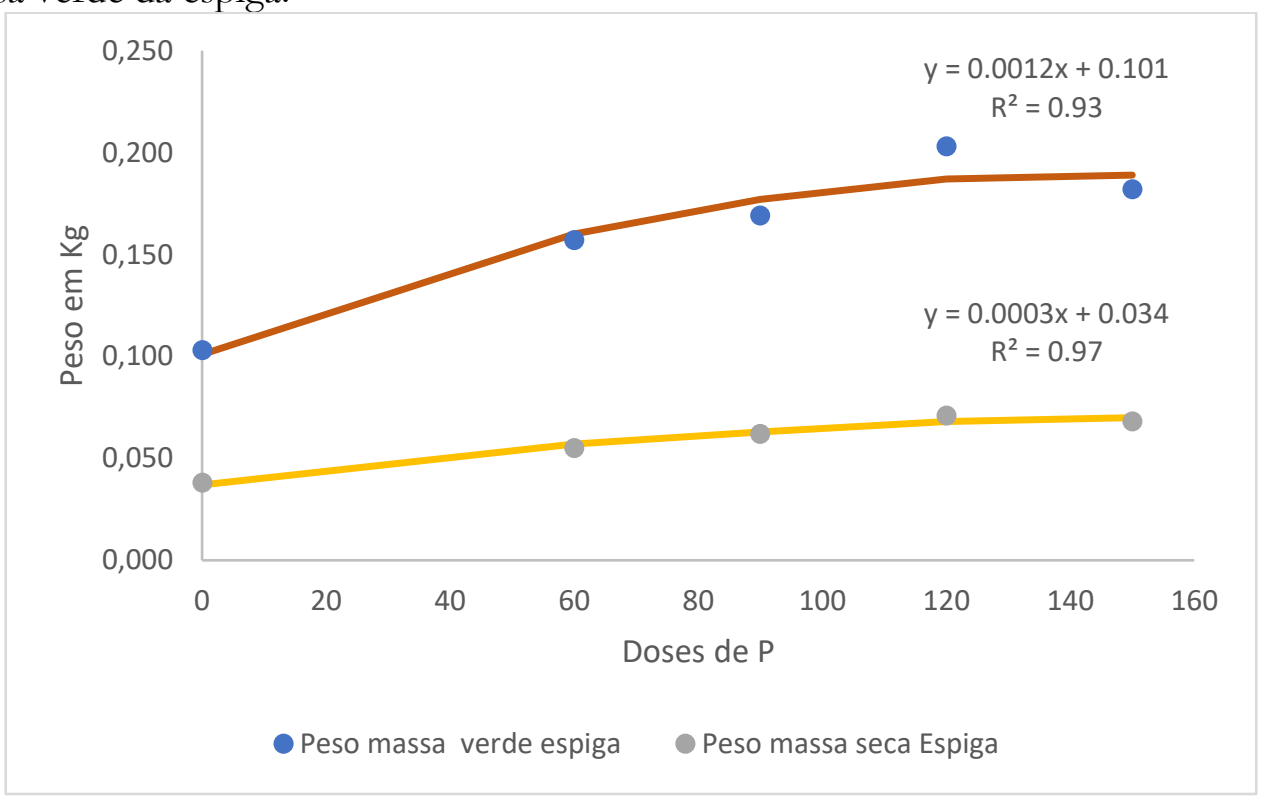

Como na figura 5, os tratamentos T1, T2, T3, T4 e T5, tiveram resultando que influenciou no aumento gradativo da massa da espiga, com o aumento das diferentes doses de fósforo nos tratamentos.

\section{Massa verde planta e massa seca}

Em relação a massa verde da planta e massa seca da planta (Figura 6), com o coeficiente de determinação de $93 \%$ e 99\%, resultados significativos a $(\mathrm{p} \leq 0,01)$, ocorreu acréscimo no aumento de massa nas dosagens deT1 aT4, e diminuição de massa T4a T5.

$\mathrm{Na}$ massa verde ocorreu um aumento de 0,175 kg a 0,466 kg, noT1(Testemunha) a T2, e diminuição de massa verde de $0,466 \mathrm{~kg}$ a $0,403 \mathrm{~kg}$, T2a T5.

$\mathrm{Na}$ relação de massa seca teve um aumento no peso de 0,069 kg a 0,127 kg, no T1 (Testemunha) a
T4, e na diminuição de massa seca T4a T5, de 0,127 kg a $0,114 \mathrm{~kg}$ (Figura 6). 
Figura 6: Diferentes doses de fósforo no plantio, com resultando significativo no peso da massa seca e peso de massa verde da planta.

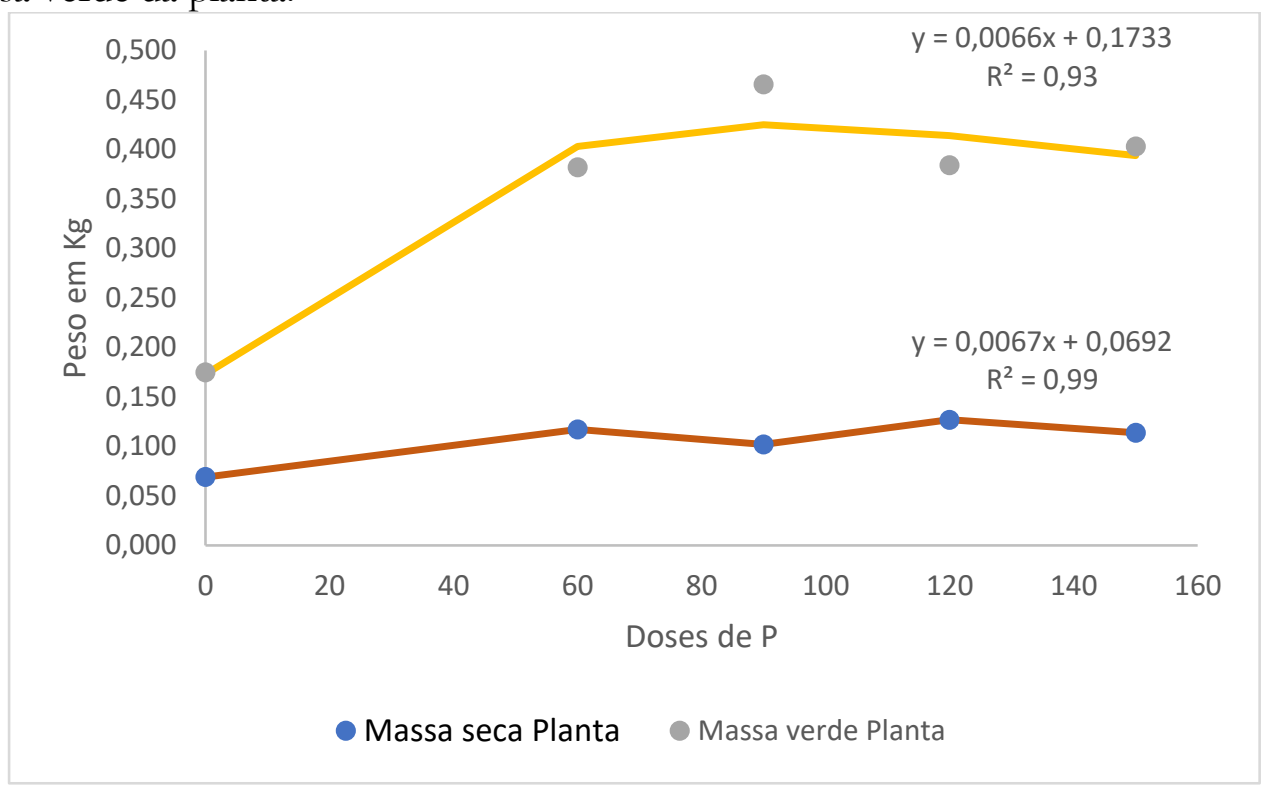

O aumento da massa verde e massa seca,

\section{REFERÊNCIAS BIBLIOGRÁFICAS}

aumentou até o tratamento T4, tendo um decréscimo na produção no tratamento T5.

De acordo com Harger et al (2007), a produção de matéria seca da cultura do milho irá aumenta conforme a dose de fósforo, independente da fonte de $\mathrm{P}$, aumentado os teores de foliares na planta de milho, contrariando os resultados do trabalho.

\section{CONCLUSÕES}

O tratamento com melhor resultando para a produção do milho, foi o tratamento $\mathrm{T} 4$, com a dosagem de $120 \mathrm{~kg}$ de $\mathrm{P} / \mathrm{ha}^{-1}$, pois proporcionou melhor resultado nas características morfológicas altura de planta (AP), altura da primeira espiga(APE), número de fileiras da espiga(NFE), número de grão por fileira(NGF), massa seca planta(MSP), massa verde planta (MVP), massa secaespiga (MSE) e massa verde espiga(MVE).

E no diâmetro do colmo de diâmetro da espiga com melhor resultando com o aumento da dosagem de fósforo de $0 \mathrm{~kg}$ de $\mathrm{P} / \mathrm{ha}^{-1} \mathrm{a} 150 \mathrm{~kg}$ de $\mathrm{P} / \mathrm{ha}^{-1}$, do tratamento $\mathrm{T} 1$ ao tratamento $\mathrm{T} 5$.

BARRETO, A. C.; FERNANDES, M. F. Produtividade e absorção de fósforo por plantas de milho em função de doses e modos de aplicação de adubo fosfatado em solo de tabuleiro costeiro, Revista Brasileira Ciências do Solo, 26:151-156, 2002.

CRUZ, J. C.; PEREIRA FILHO, I. A.; ALVARENGA, R. C.; GONTIJO NETO, M. M.; VIANA, J. H. M.; OLIVEIRA, M. F. de; MATRANGOLO, W. J. R.; ALBUQUERQUE FILHO, M. R. de. Plantio. In: CRUZ, J. C. (Ed.). Cultivo do milho. 6. ed. Sete Lagoas: Embrapa Milho e Sorgo, (Embrapa Milho e Sorgo. Sistema de produção, 1) Ano de 2010.

GIRACCA, E, M. N; NUNES, J, L. S;AGROLINK; Fósforo, Ano de 2016, Encontrado em;HTTPS://www.agrolink.com.br/fertili zantes/fosforo_361445.html, Acessado em $19 / 05 / 2018$.

HARGER. N.; BRITO, O. R.; ROLISH.R. Avaliação de fontes e doses de fósforo no crescimento inicial do milho, v. 28, n. 1, p. 3944, jan./mar. 2007, Ciências Agrárias, Londrina.

INMET; Instituição nacional de metrologia de Goianésia, ministério da agricultura, pecuária e abastecimento, acessado em: 24/11/2018. 
LIMA, L. B; BATISTA, K. D ; ROCHA, P, R. R; AQUINO, S, T. M ; SANTOS, R. F ; CASTRO, T. Desenvolvimento de milho cultivado sob doses de fósforo no cerrado de Roraima em sistema de plantio direto, 2016, Rua Sete de Setembro, 231- Canarinho - 69.306-530 - Boa Vista/RR.

LUCENA, F, C. L; OLIVEIRA, F.A; SILVA, I. F; ANDRADE, A. P. Resposta do milho a diferentes dosagens de nitrogênio e fósforo aplicados ao solo, 16/03/2000, Protocolo 029/00.

MACHADO, J, R. A: Embrapa - Artigo - excesso de chuvas e a cultura do milho- pesquisadores da Embrapa milho e sorgo, publicado em 12/01/2016. Encontrando em:HTTPs://www.embrapa.br/en/busca-denoticias/-/noticia/8900890/artigo---o-excessode-chuvas-e-a-cultura-do-milho, Acessado em: $24 / 11 / 2018$

PADRO, R. M; FERNANDES, F. M; ROQUE, C. G: Resposta da cultura do milho modo de aplicação e doses de fósforo em adubação de manutenção, vol. 25, núm. 1, 2001, pp. 83-90 R. Bras. Ci. Solo, 25:83-90, Ano de 2001.

SEIXAS. W; Plano de Negócio Excel, 11/04/2017, disponível em: HTTPS://www.dm.com.br/cotidiano/2017/04 /goias-confirma-4o-lugar-em-producao-degraos.html, Acessando em: 25/03/2018.

SORATTO, R. P.; PEREIRA, M.; COSTA, T. A. M.; LAMPERT, V. N. Fontes alternativas e doses de nitrogênio no milho safrinha em sucessão à soja. Revista Ciência Agronômica, 2010. v.41, p.511-518

VASCONSELLOS, C. A; PITTA, G, V. E; FRANCA, G. E; ALVES, V, M. C; Embrapa Milho e Sorgo, Publicado em janeiro de 2000 pela revista cultivar grandes culturas $\mathrm{n}^{\circ} 12$, disponível em:HTTPs://www.grupocultivar.com.br/artigo s/fosforo-para-o-milho, Acessado em: $25 / 03 / 2018$. 